ION MĂRII

\title{
RESCRIEREA ARTICOLELOR LEXICOGRAFICE ÎNTREGITOARE (= RECUPERATOARE) DIN DLR (serie nouă) ÎN MDA. ÎNSEMNARE LEXICOGRAFICĂ
}

\author{
In amintirea eminentelor DLR-iste clujence, \\ lingvistele Ioana Anghel și Felicia Șerban
}

\section{Precizări i n t rod u c ti v e:}

1.1. În primul rând, trebuie precizat că prin ceea ce, convențional (desigur), numim articol lexicografic în tre g i tor (= de întregire) sau r e c u p e r a t or tipologizăm acel articol lexicografic care este, întotdeauna, s u b o r d o n a t unui articol lexicografic i nd e p e n d e nt, care, acest articol lexicografic propriu-zis, urmează, într-o nouă ediție sau o nouă versiune lexicografică (cum, spre exemplu, este MDA în raport cu DA și DLR), să fie întregit prin valorificarea riguroasă a tuturor datelor lingvistice inedite oferite de articolul lexicografic întregitor, date ce, trebuie subliniat, se pot referi, în principiu, nu numai la forma lexicală şi la sursa ei bibliografică (cum, incomplet, se afirmă în DLR 2006/X), ci la toate componentele structurii unui articol lexicografic independent, consacrat, adică, unei unități lexicale autonome mono- sau pluriforme.

1.2. Articolul lexicografic recuperator este, dacă desigur ai fost informat asupra existenței lui și asupra caracteristicilor sale principale, foarte ușor de recunoscut (= identificat), având în vedere următoarele trei indicii:

a. Prezența, după „forma-titlu” și a categoriei morfologice a acesteia, a semnului =, urmat de „cuvântul-titlu” al articolului lexicografic independent subordonator, c e l c e tre bui e întregit adică.

$b$. Absența secțiunii consacrate etimologiei, excepție făcând cazurile când, sub aspect etimologic, se menționează și un alt etimon decât cel prezent în articolul ce urmează să fie întregit sau când se corectează forma etimonului propus în articolul subordonator. $\mathrm{Cu}$ excepția articolelor lexicografice recuperatoare, în DLR (s.n.) nu există articol lexicografic independent din care să lipsească secțiunea consacrată etimologiei ,,cuvântul-titlu”, indiferent de soluția etimologică propusă de cele 3 redacții ale DLR (s. n.), soluție avizată de comisia de etimologie a dicționarului.

c. Paragrafarea sensului sau sensurilor ce urmează să fie recuperate, paragrafare realizată conform schemei semantice a cuvântului de întregit.

1.3. După precizările de mai sus, este momentul să arătăm că, in toate cazurile când articolul lexicografic independent (= subordonator) din DLR ce urma să fie întregit cu informația lingvistică = lexicografică prezentă în articolul lexicografic 
recuperator din DLR nu a fost încă rescris și publicat deja în MDA, atunci și numai atunci redactorul MDA căruia îi revenea sarcina să rescrie articolul recuperator din DLR trebuia, pe de o parte, să elaboreze, în locul articolului lexicografic recuperator = întregitor, un simplu articol lexicografic de trimitere, iar, pe de altă parte, să-1 atenționeze asupra existenței unui articol lexicografic recuperator pe redactorul căruia îi revenea misiunea de a rescrie articolul lexicografic independent la care suntem trimiși chiar prin titlul articolului întregitor.

1.4. După precizarea de sub 1.3., trebuie subliniat faptul că rescrierea articolului lexicografic întregitor $=$ recuperator fie ca articol lexicografic independent, fie numai ca articol lexicografic de trimitere e s te 1 a fe $1 \mathrm{de} g \mathrm{ressit} \breve{\text {. }}$

1.5. În cazurile (foarte numeroase) când articolul lexicografic independent (=, adică, cel ce trebuia întregit) a fost redactat și publicat înainte de rescrierea articolului întregitor, atunci era corect ca redacția MDA să păstreze articolul lexicografic recuperator transpunându-1, însă, în maniera redacțională a acestui mic dicționar academic.

1.6. Articolul lexicografic întregitor nu este o născocire a DLR, s. n., ci el este o inovație lexicografică a DA, invenție absolut necesară câtă vreme (nu numai principial, ci şi practic) fișierul dicționarului este (și este bine că este aşa) m e r e u d e s c h i s, pe de o parte, iar, pe de altă parte, dicționarul s-a publicat și se publică fragmentar (în coli, fascicole şi/sau volume).

Notă. Pentru înțelegerea corectă a observațiilor redactate cu prilejul grupajului de note lexicografice ce urmează să apară în Lucrările Celui de-al XIX-lea Simpozion Internațional de Dialectologie (volum aflat în lucru, cum ne informează colegul D. Loșonți), am redactat și precizările de mai sus (v. nota lexicografică nr. 2. chelarábă, chelerábă, cherăbábă ${ }^{*}$, corelábă etc. = calarábă), precizări repetate și cu prilejul redactării prezentei însemnări lexicografice.

\section{Note lexicografice e $x$ e $\mathrm{m} p \mathrm{l}$ i f i c a t o a r e:}

2.1. „UCIÓCI s. m. pl. = ocioc”.

2.1.1. În DLR 1969/104, este lucrat următorul articol lexicografic independent:

„OCIÓC s. m. 1. (Prin Olt. și sud-vestul Transilv.; mai ales la pl.) Ştiulete de porumb slab dezvoltat (cu boabe foarte rare) [...]; știulete desfăcut de boabe [...]; tuleu care rămâne pe porumbiște [...]. (Învechit, rar) Paie [...]. 2. (Prin Olt.; la pl.) Vrejuri și păstăi care rămân după ce au fost scoase boabele de fasole sau de mazăre; rămășiță [...]. 3. (Regional) Unealtă cu ajutorul căreia se desfac boabele de porumb de pe știulete [...]. - Pl.: ocioci. - Și: ociógi s. m. pl. [...]. - Cf. magh. o c s ú k (pl. lui ocsu)".

2.1.2. În DLR 2002/13, este lucrat următorul articol lexicografic recuper a t or:

„UCIÓCI s. m. pl. = ocioc. 4. (Regional) Ceea ce rămâne după ce s-au cernut sâmburii de bostan pisați (Băuțar - Caransebeş). Cf. VICIU, GL. 5. (Regional) 
Bucățele de aluat care se folosesc în loc de tăieței, fierte în supă sau în lapte; (popular) colărezi (Brădișorul de Jos - Oravița). Com. LIUBA".

2.1.3. În MDA 2003, III/803, este lucrat următorul articol lexicografic i ndependent:

„ocioc sm [At: ANON. CAR./ V: ogi smp/ Pl: ocil E: mg ocsúc] 1 (Olt; Trs; mpl) Știulete de porumb slab dezvoltat cu boabe foarte rare. 2. (Olt; Trs; mpl) Știulete desfãcut de boabe. 3 (Olt; Trs; mpl) Tuleu de porumb. 4 (Olt; Trs; mpl) Paie. 5 (Olt; lpl) Vrejuri și păstăi care rămân după ce au fost scoase boabele de fasole sau de mazăre. 6. (Reg) Unealtă cu ajutorul căreia se desfac boabele de porumb de pe știulete",

articol care, $1 \mathrm{acunar}$ (= n ê̂ntre gitor) și în maniera semasiologică a micului nostru dicționar academic, rescrie articolul de sub 2.1.1., cu următoarea greșeală: nu din „mg ocsúc”, ci „cf. magh. ocsúk (pl. lui ocsu)”.

1.1.4. În MDA 2003, IV/1098, este lucrat, profund greșit, următorul articol lexicografic independent:

„,ucioci smp [At: VICIU, GL./ E: nct] (Reg) 1 Resturi care rămân după ce s-au cernut sâmburii de bostan pisați Si: ociuc. 2 Bucățele de cocă folosite în loc de tăiței, fierte în supă sau în lapte Si: (pop) colărezi (1)",

articol ce, din ignoranță lexicografică, rescrie articolul lexicografic r e c u perat or de sub 2.1.2. ca articol 1 e x i c og rafic independent, forma de plural ucióci fiind considerată, astfel, ca reprezentând o altă unitate lexicală independentă, sinonimă cu unitatea lexicală ocióc și având „etimologia necunoscută", când, în realitatea lexicografică înregistrată de redacția DLR (s. n.), avem, de fapt, de-a face, ca și pentru forma de plural ociógi, doar cu o variantă lexicală a formei-titlu ocioc, cum, foarte clar, ne anunță chiar redacția clujeană a DLR 2002/13 prin formularea titlului articolului lexicografic (întregitor): „UCIÓCI s. n. pl. = ocioc”.

2.1.5. Concluzionând, vom spune că, rescriind c o r e c t (= în conformitate cu realitatea lexicografică conținută în articolul lexicografic întregitor din DLR 2002/13), redacția MDA trebuia să elaboreze, pentru articolul lexicografic recuperator, un simplu articol lexicografic de trimitere: „ucioci $s m p$ vz ocioc”, pe de o parte, iar, pe de altă parte, să completeze articolul lexicografic independent de sub 2.1.3. cu varianta lexicală UCIÓCI și cu introducerea celor două sensuri adăugite de redacția DLR 2002/13.

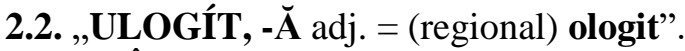

2.2.1. În DLR 1969/191, este lucrat următorul articol lexicografic independent:

„OLOGÍT, -Ă adj. Care a devenit olog (I 1); paralizat de picioare. Cf. DDRF, ALRM II/I h 162. - Pl.: ologiți, -te. - V. ologi”.

2.2.2. În DLR 2002/61, este lucrat următorul articol lexicografic recuperator: 
„ULOGíT, - $\breve{\text { A }}$ adj. = (regional) ologit. Cf. NALR-B I h 122/71, ib. h 123/71”.

2.2.3. În MDA 2003, III/822, este lucrat următorul articol lexicografic ind e pendent:

„ologit, -ă $a$ [At: DDRF/ Pl: iți,-te/ E: ologi] 1-2 Care a devenit olog (1,3). 3 Paralizat de picioare",

articol ce, lacunar și în maniera semasiologică a MDA, rescrie articolul de sub 2.2.1.

2.2.4. În MDA 2003, IV/1105, este lucrat următorul articol lexicografic independent:

„ulogit, -ă $a$ [At: NALR-B I h 122/71/ Pl: ițit, e/ E: nct] (Reg) Ologit”,

articol ce, din ignoranță lexicografică, rescrie articolul lexicografic recuperator de sub 2.2.2. ca articol lexicografic independent, formele ulogít și ulogítă fiind considerate, astfel, ca reprezentând alte două unităţi lexicale independente, cu „etimologia necunoscută”, când, în realitatea lexicografică înregistrată de redacția DLR (s. n.), avem de-a face cu două variante lexicale ale formelor-titlu ologít, ologítă, cum, de altfel, ne anunță chiar redacția clujeană a DLR 2002/61 prin formularea titlului articolului lexicografic (întregitor):

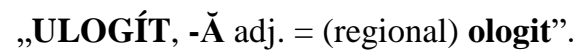

2.2.5. Concluzionând, vom spune că, rescriind c o r e c t (= în conformitate cu realitatea lexicografică conținută în articolul lexicografic întregitor din DLR 2002/61), redacția MDA trebuia, simplu, să elaboreze, în locul articolului lexicografic r e c u p e r a t o r, doar un articol lexicografic de trimitere: ,ulogit, $\sim \mathbf{a} a v z$ ologit, $\sim \breve{a} "$, pe de o parte, iar, pe de altă parte, să completeze articolul lexicografic independent de sub 2.2.3. cu variantele lexicale ulogít, -ă.

2.3. ,UMIZÍ vb. IV = (regional) omizi ${ }^{2}$ ”.

2.1.1. În DLR 1969/210, este lucrat următorul articol lexicografic i ndependent:

„OMIZÍ ${ }^{2}$ vb. IV. I n t r a n z. (Transilv.) A clipi din ochi. V. m i j i. Cf. CIHAC, II, 195. $\diamond \mathrm{R}$ e fl. u n i p e r s. E x p r. A se omizi de ziuă = a se crăpa de ziuă [...]. - Prez. ind.: omizesc. - Și: omiji vb. IV. CIHAC, II, 195. - Din slavon.: 0 M’..$\tilde{A} J$ I T I. .

2.3.2. În DLR 2002.143, este lucrat următorul articol lexicografic recuper a tor:

„UMIZÍ vb. IV = (regional) omizi ${ }^{2}$. (Î n e x p r.) Umezește (sau omizește) a râde sau umezază a râde, o umezat a râde = a schița un zâmbet, a surâde, a zâmbi. V m i j i ${ }^{1}$ (II). Cf. ALR II/I MN 52, 2305 bis/95, 310, A I 24. $\diamond \mathrm{R}$ e f 1. u n i p e r s. A se umizi de ziuă = a se crăpa de ziuă [...]. NEGRUZZI, S. I, 227, cf. CIHAC, II, 195, TDRG [...]. - Prez. ind.: umizește. - Și: umezí vb. IV, umezá (ALR II/I MN 52, 2305 bis/310) vb. I". 
2.3.3. În MDA 2003, III/826, este lucrat următorul articol lexicografic independent:

,omizi ${ }^{2}$ [At: CIHAC, II, 195/ V: (reg) iji/ Pzi: zesc/ E: slv 0 M" . Ã J I T I. ] 1 vi (Trs) A clipi. 2 vrim (Reg; îe) A se $\sim$ de zuă A se crăpa de ziuă",

articol ce, 1 a c u n a r și în maniera semasiologică a MDA, rescrie articolul de sub 2.3.1., cu următoarea greșeală: abrevierea vrim $=$, în articolul ce a fost rescris, vru, adică, „traducând”, nu „,verb reflexiv impersonal”, ci, corect, „verb reflexiv unipersonal".

2.3.4. În MDA 2003, IV/1115, este lucrat următorul articol lexicografic independent:

„umizi [At: NEGURZZI, S. I, 227/ V: umezi, umeza/ Pzi: 3 zește/ E: nct] (Reg) $1 v$ A omizi $^{2} .2$ (Îe) Umezește a râde. Schițează un zâmbet. 3 $v r u(\hat{e})$ A se $\sim$ de ziuă A se crăpa de ziuă",

articol ce, din ignoranţă lexicografică, rescrie articolul lexicografic r e c u p e r a t o r de sub 2.3.2. ca articol lexicografic i n d e p e n d e n t, forma verbală umizí fiind, astfel, considerată ca reprezentând o altă unitate lexicală independentă, cu variantele lexicale umezí și umezá și cu „etimologia necunoscută”, când, în realitatea lexicografică înregistrată de redacția DLR (s. n.), avem de-a face cu alte trei variante lexicale ale formei-titlu omizí, cum, de altfel, ne anunţă chiar redacția clujeană a DLR 2002/143 prin formularea titlului articolului lexicografic (întregitor): „UMIZÍ vb. IV = (regional) omizi ${ }^{2}$ ".

2.3.5. Concluzionând, vom spune că, rescriind c o r e c t (= în conformitate cu realitatea lexicografică conținută în articolul lexicografic întregitor din DLR 2002/143), redacția MDA trebuia să elaboreze, în locul articolului lexicografic r e c u p e r a or, trei articole lexicografice de trimitere: „umeza $v v z$ omizi ${ }^{2}$ ", „umezi $v v z$ omizi $^{20}$ şi „umizi $v v z$ omizi $^{2}$ ”, pe de o parte, iar, pe de altă parte, să completeze articolul lexicografic in de pe ndent de sub 2.3.3. cu variantele lexicale: umizí, umezí, umezá, precum, desigur, și cu e x p re s i a: Umezește (sau omizește) a râde sau umezază a râde, o umezat a râde = a schița un zâmbet, a surâde, a zâmbi.

2.4. „UMIZÍRE s. f. $=$ (regional) omizire ${ }^{2}$ ".

2.4.1. În DLR 1969/210, este lucrat următorul articol lexicografic i ndepende $\mathrm{nt}$ :

„OMIZÍRE² s. f. (Învechit, Transilv.) Revărsatul zorilor [...]. CIHAC, II, 195, cf. ALEXI, W. - V. omizi ${ }^{2}$."

2.4.2. În DLR 2002/143, este lucrat următorul articol lexicografic recuperat or:

„UMIZÍRE s. f. = (regional) omizire ${ }^{2}$ [ [...] POGOR, HENR [...]. \âmbire, surâs. Cf. GHEȚIE, R.M. - Pl.: umiziri". 
2.4.3. În MDA 2003, III/826, este lucrat următorul articol lexicografic independent:

„omizire ${ }^{2} s f$ [At: CIHAC, II, 195/ E: omizi²] (Trs; înv) Luminare de ziuă”,

articol ce, lacunar și în maniera semasiologică a MDA, rescrie articolul de sub 2.4.1.

2.4.4. În MDA 2003, IV/1115, este lucrat următorul articol lexicografic i n d e pendent:

„umizire $s f$ [At: POGOR, HENR. 233/26/ Pl: $\sim r i /$ E: umizi] 1 Omizire². 2 Surâs",

articol ce, din ignoranță lexicografică, rescrie articolul lexicografic r e c u p e r a t o r de sub 2.4.2. ca articol lexicografic in d e p e $n d$ e $n \mathrm{t}$, forma substantivală umizíre fiind, astfel, considerată ca reprezentând o altă unitate lexicală independentă, când, în realitatea lexicografică înregistrată de redacția DLR (s. n.), avem de-a face doar cu o variantă lexicală a formei-titlu omizíre, cum, de altfel, ne anunță chiar redacția clujeană a DLR 2002/143 prin formularea titlului articolului lexicografic (întregitor): „UMIZÍRE s. f. = (regional) omizire ${ }^{2}$.

2.4.5. Concluzionând, vom spune că, rescriind c o r e c t (= în conformitate cu realitatea lexicografică conținută în articolul lexicografic întregitor din DLR 2002/143), redacția MDA trebuia să elaboreze, în locul articolului lexicografic r e c u p e r a t o r, doar un articol lexicografic de trimitere: „umizire $s f v z$ omizire 2 ", pe de o parte, iar, pe de altă parte, să întregească articolul lexicografic i n d e p e nd e n t de sub 2.4.3. cu varianta lexicală umizíre, (sub)sensul „zâmbire, surâs” și pl. umiziri.

2.5. „UNDÉR s. n. = (regional) ghionderă”.

2.5.1. În DA 1934/261, este lucrat următorul articol lexicografic i ndependent:

„GHIONDÉRĂ s. f. Perche. - Prăjină. H. X 111. Mânând luntrea $\mathrm{cu}$ ghionderul. DUNĂREANU, R. 124 [...]. [Și: ghiondér s. a., ghiondiríu subst. = prăjină de măsurat [...], ghiondic subst. (citat între cuvintele referitoare la plutire) H. II 332.] - Din turc. göonder «prăjină». CAPIDAN".

2.5.2. În DLR 2002/175, este lucrat următorul articol lexicografic recuper a tor:

„UNDÉR s. n. = (regional) ghionderă. Prăjină lungă, ascuțită la unul dintre capete, care, înfingându-se pe fundul apei, face să înainteze barca. V. r a s c ă, s a c o v i ță. Cf. T. DIAL. D. 843. Din anu-acesta am inceput să-nvăț și io să mân barca, și la rame, și la under ib.".

2.5.3. În MDA 2002/537, este lucrat următorul articol lexicografic ind e pendent: 
,ghionderă $s f$ [At: LTR/ V: del, der $s n /$ Pl: re/ E: tc gönder] Prăjină care servește pentru a pune în mișcare o ambarcațiune mică [...]",

articol ce, 1 a c u n a r și în maniera semasiologică a MDA, rescrie articolul de sub 2.5.1.

Note:

1. Articolul lexicografic independent ghionderă din MDA 2002/537 nu numai că aste o rescriere lacunară a articolului lexicografic independent din DA 1934/261, ci el este în același timp și o rescriere profund greșită prin interpretarea variantelor lexicale ghiondic și ghiondiriu drept unități lexicale aparte, redactând, astfel, în locul a încă două articole lexicografice de trimitere (așa cum, corect, s-a procedat cu variantele ghiondel și ghionder), următoarele două articole lexicografice i n d e p e n d e n t e:

a) ,ghiondic $s$ [At: H II, 332/ Pl: ?/ E: $n c t$ ] (Ned) Citat între cuvintele referitoare la plutire".

b) ,ghiondiriu $s$ [At: PAMFILE, J. II, ap. DA/ Pl: ii/ E: Cf. ghionderă] Prăjină de măsurat”.

2. Pentru formele lexicale ghiondér, ghiondéră, ghiondél, ghiondíc, ghiondiriu și undér, a se vedea, neapărat, și SUCIU 2010/359, precizând că Emil Suciu etimologizează, corect, extern sau intern, toate cele şase forme lexicale.

2.5.4. În MDA 2003, IV/1119, este lucrat următorul articol lexicografic i ndepende $\mathrm{t}$ :

„under sn [At: T. DIAL. D. 843/ Pl: ?/ E: nct] (Reg) Prăjină lungă, ascuțită la unul dintre capete, care, înfingându-se pe fundul apei, face să înainteze barca. Si: rașcă, sacoviță",

articol ce, din ignoranță lexicografică, rescrie articolul lexicografic r e c u p e r a t o r de sub 2.5.2. ca articol lexicografic i n d e p e n d e n t, forma substantivală undér fiind, astfel, considerată ca reprezentând o altă unitate lexicală, când, în realitatea lexicografică înregistrată de redacția DLR (s. n.), avem de-a face doar cu o variantă lexicală a formei-titlu ghionderă, cum, de altfel, ne avertizează chiar redacția clujeană a DLR 2002/175 prin formularea titlului articolului lexicografic: „UNDÉR s.n. = (regional) ghionderă”.

2.5.5. Concluzionând, vom spune că, rescriind c o r e c t (= în conformitate cu realitatea lexicografică conținută în articolul lexicografic întregitor din DLR 2002/175), redacția MDA trebuie să elaboreze, în locul articolului lexicografic r e c u p e r a t o r, doar un articol lexicografic de trimitere: ,under sn $v z$ ghionderă”, pe de o parte, iar, pe de altă parte, să întregească articolul lexicografic i n d e p e n d e n t de sub 2.5.3. cu varianta lexicală undér.

2.6. „UNINEÁ s. f. = (Ornit.; regional) minunea (1)”.

2.6.1. În DLR 1965-1968/578, este lucrat următorul articol lexicografic independent:

„MINUNEÁ s. f. (Regional) Pasăre mai mică decât un porumbel, cu penele pestrițe, care trăiește în munți, și care iese numai noaptea; (regional) minuniță, 
cucuvea (Aegolius funereus). [...]. (prin nord-estul Transilv.) Privighetoare [...]. $-\mathrm{Pl}$.: minunele. - Minune + suf. $-e a "$.

2.6.2. În DLR 2002/213, este lucrat următorul articol lexicografic recuperator:

„UNINEÁ s. f. = (Ornit.; regional) minunea (1) (Aegolius funercus) (Frătăuții Vechi - Rădăuți). Unineaua e așa de mare ca un ou de curcă sau ceva și mai mare. ap. MARIAN, O. I, 436, cf. JAHRESBER. XII, 136, 148, DL, BĂCESCU, PĂS. 172, 258".

Notă. Menționarea, după forma-titlu (v. infra) minuneá, a cifrei (1), absentă (firesc) din DLR 1965-1968, nu era, credem, necesară; indicarea denumirii științifice (= latinești) era, desigur, suficientă pentru a sublinia că e vorba de sensul și nu de subsensul înregistrat de redacția DLR 1965-1968/578.

2.6.3. În MDA 2003, III/576, este lucrat următorul articol lexicografic independent:

„,minunea $s f$ [At: MARIAN, O. I, 435/ PI: ele/ E: minune + -ea] [...]. 3 (Reg) Pasăre mai mică decât un porumbel, cu penele pestrițe, care trăiește în munți și care iese numai noaptea Si: (reg) minuniță, cucuvea (Aegolius funereus) [...]",

articol ce, lacunar și în maniera semasiologică a MDA, rescrie articolul de sub 2.6.1., cu adăugirea (redacțională a) sensurilor: „1-2 (Reg; șhp) Minune (2) (mică) Si: (rar) minunică (1-2), (reg) minuniță (1-2)".

2.6.4. În MDA 2003, IV/1125-1126, este lucrat următorul articol lexicografic independent:

„uninea $s f$ [At: MARIAN, O. I, 435/ Pl: ele/ E: pbl fo cf și minunea] (Reg) Pasăre de noapte mai mică decât porumbelul, cu pene pestrițe și aripi scurte, care trăiește în pădurile de molid Și: (reg) minunea (Aegolius funercus)",

articol ce, din ignoranță lexicografică, rescrie, critic (?!), articolul lexicografic r e c u p e r a t o r de sub 2.6.2. ca articol lexicografic in d e pe nd e n t, forma substantivală uninea fiind, astfel, considerată ca reprezentând o altă unitate lexicală independentă, cu etimologia: ,pbl fo cf și minunea" și sinonimă cu regionalismul minunea. $\mathrm{Nu}$, hotărât lucru (nu numai de redacția DLR 2002/213, ci și de redacția națională a DLR prin membrii comisiei de etimologie), forma lexicală unineá nu este un alt cuvânt (de proveniență „,probabil onomatopeică”), ci doar o variantă lexicală a derivatului minuneá.

2.6.5. Concluzionând, vom spune că, rescriind c o r e c t (= în conformitate cu realitatea lexicografică conținută în articolul lexicografic întregitor din DLR 2002/213), redacția MDA trebuia să elaboreze, în locul articolului lexicografic r e c u p e r a tor, următorul articol lexicografic de trimitere: ,uninea $s f \mathrm{v}$ minunea", pe de o parte, iar, pe de altă parte, să întregească articolul lexicografic i n d e p e $\mathrm{n} d$ e $\mathrm{n} t$ de sub 2.6.3. cu varianta lexicală uninea.

Notă. Denumirea științifică (= cea latinească) a păsării numite (și) minunea este redată greșit și neunitar (în ceea ce privește determinantul) atât în DLR, cât și în MDA. 
2.7. „ÚNTERȘLAG s. n. = teșlag”.

2.7.1. În DLR 1982/226, este lucrat următorul articol lexicografic i nde pe nde nt:

„TEȘLÁG s. n. (Tipogr.) Material tipografic din plumb, care se pune în josul paginii pentru a susține rândurile; rândul alb de jos. Cf. V. MOLIN, V. T. 68, 80, L. ROM. 1965, 252. - Pl.: teșlage. - Şi: teșleág (pl. teșlege LTR $^{2}$ ) s. n. - Din germ. Unterschlag".

2.7.2. În DLR 2002/238, este lucrat următorul articol lexicografic recuperator:

„ÚNTERȘLAG s. n. = teșlag. Jos îi punem un reglete cât zațul numit unterșlag. ROMANESCU, ZET,. 53”.

2.7.3. În MDA 2003, IV/905, este lucrat următorul articol lexicografic independent:

„teșlag sn [At: V. MOLIN, V. T. 68/ V: (înv) leag (Pl: ege)/ Pl: age/ E: ger Unterschlag] (Tip) Material tipografic din plumb, care se pune în josul paginii pentru a susține rândurile. 2 Rândul alb de jos",

articol ce, 1 a c u n a r şi în maniera semasiologică a MDA, rescrie articolul de sub 2.7.1.

2.7.4. În MDA 2003, IV/1129, este lucrat următorul articol lexicografic independent:

„unterșlag $s n$ [At: ROMANESCU, ZEȚ. 53/ Pl: ?/ E: nct] Teşlag”,

articol ce, din ignoranță lexicografică, rescrie articolul lexicografic r e c u p e r a t o r de sub 2.7.2. ca articol lexicografic in d e p e $n d$ e $n t$, forma lexicală únterșlag fiind, astfel, considerată ca reprezentând o altă unitate lexicală independentă, cu „etimologia necunoscută”, când, în realitatea lexicografică înregistrată de redacția DLR (s. n.), avem de-a face doar cu o altă variantă lexicală a formei-titlu teșlág, cum, de altfel, ne anunță chiar redacția clujeană a DLR 2002/238 prin simpla formulare a titlului articolului lexicografic (întregitor): „ÚNTERȘLAG s. n. = teșlag".

2.7.5. Concluzionând, vom spune că, rescriind c o r e c t (= în conformitate cu realitatea lexicografică conținută în articolul lexicografic întregitor din DLR 2002/238), redacția MDA trebuia să elaboreze, în locul articolului lexicografic r e c u p e r a t o r, doar un articol lexicografic de trimitere: „unterșlag $s n$ vz teșlag”, pe de o parte, iar, pe de altă parte, să întregească articolul lexicografic independent de sub 2.7.3. cu varianta lexicală únterșlag.

2.8. „ÚRDIE s. f. $=$ ordie”.

2.8.1. În DLR 1969/282-283, este lucrat următorul articol lexicografic ind e pendent: 
„ÓRDIE s. f. (Învechit) 1. Oaste (mai ales de turci sau de tătari); tabără militară; hoardă. [...]. NECULCE, L. 242. [...]. 2. Mulțime mare de oameni, gloată; droaie. [...] - Accentuat și: ordíe (CIHAC, II, 601, TDRG). - Pl.: ordii. - Și: hórdie, órde, úrdie (accentuat și urdíe TDRG) s. f. - Din bg. ордия, scr. ordija”.

2.8.2. În DLR 2002/305, este lucrat următorul articol lexicografic recuperator:

„ÚRDIE s. f. = ordie. 1. Oaste (mai ales de turci sau de tătari); tabără militară, hoardă. Să strângă toți oamenii... care undi-i va afla..., veri la uraș, veri la urdii (a. 1646). IORGA, S. D. V, 182. [...]. 2. Mulțime mare (de oameni); ceată; gloată; droaie. [...] (Regional) Familie (numeroasă). [...]. - Accentuat și: urdíe. - Pl.: urdii și (învechit) urdie".

2.8.3. În MDA 2003, III/842, este lucrat următorul articol lexicografic independent:

„ordie $s f$ [At: NECULCE, L. 242/ V: (reg) ho , de, ur / A și: ordie/ Pl: iil E: bg ордия, srb ordija] (Înv) 1-2 Oaste (de turci sau) de tătari. 3 Tabără militară. 4 Hoardă. 5 Mulțime de oameni Și: (pop) gloată, (reg) droaie",

articol ce, 1 a c u n a r și în maniera semasiologică a MDA, rescrie articolul de sub 2.8.1., omițindu-se forma accentuată urdíe.

2.8.4. În MDA 2003, IV/1137, este lucrat următorul articol lexicografic i n d e pe nde nt:

,urdie $s f$ [At: (a. 1646) IORGA, S. D. V, 182/ Pl: ii și (înv) / E: nct] Oaste (mai ales de turci sau de tătari) Si: ordie. 2 Tabără militară. 3 Hoardă (2). 4 Mulțime mare (de oameni) Si: ceată (19), gloată (1), droaie (2). 5 (Reg) Familie (numeroasă)",

articol ce, din ignoranță lexicografică, rescrie articolul lexicografic r e c u p e r a t o r de sub 2.8.2. ca articol lexicografic i n d e p e n d e $\mathrm{n}$ t, forma lexicală úrdie fiind, astfel, considerată ca reprezentând o altă unitate lexicală independentă, cu ,etimologia necunoscută" și având ca primă atestare ,a. 1646 [...]”, când, în realitatea lexicografică înregistrată de redacția DLR (s. n.), avem, de fapt, de-a face cu o altă variantă lexicală a formei-titlu órdie, cum, foarte clar, ne anunță chiar redacția clujeană a DLR 2002/305 prin formularea titlului articolului lexicografic (întregitor): „ÚRDIE s. f. = ordie”.

2.8.5. Concluzionând, vom spune că, rescriind c o r e c t (= în conformitate cu realitatea lexicografică conținută în articolul lexicografic întregitor din DLR 2002/305), redacția MDA trebuia să elaboreze, în locul articolului lexicografic r e c u p e r a t o r, un simplu articol lexicografic de trimitere: „urdie $s f$ vz ordie”, pe de o parte, iar, pe de altă parte, să întregească articolul lexicografic independent de sub 2.8.3. cu varianta lexicală úrdie și (sub)sensul (reg.) „familie (numeroasă)”.

2.9. „URITÁC s.n. = oritac”.

2.9.1. În DLR 1969/308, este lucrat următorul articol lexicografic ind e pendent: 
„ORITÁC subst. (Prin Ban.) Otic. ALRM SN h 17/47 [...]. - Pl.: ? - Şi: oritég subst. - din scr. oritak".

Notă. Sursa: „ALRM SN h 17/47” =, în abrevierea utilizată de noi, ALRM II, s. n., 1956 are, cum ne avertizează chiar sursa precizată (v. colțul de sus din partea dreaptă, sub numărul hărții mici $=$ colorate $=$ i nterpretative), şi un corespondent n e i n t e r p r e t a t i v: ALR SN I h 23 =, în abrevierea folosită de noi, ALR II, s. n., 1956; ambele hărți publicând, neinterpretativ = integral, și interpretativ = parțial (fără menționarea, de regulă, a pluralului și a accentului) răspunsurile înregistrate fonetic de E. Petrovici la întrebarea lexicală onomasiologică pentru poziția ,,5012 = otic (lopățica cu care se curăța fierul [plugului] de pământ" din Chest. ALR II 1988. Fac această precizare, pentru că, dacă redactorul clujean al articolului lexicografic reprodus integral sub 2.9.1. ar fi consultat și harta neinterpretativă, ar fi avut, pe de o parte, confirmarea plasării corecte a accentului privind forma-titlu, iar, pe de altă parte, ar fi văzut că forma lexicală arítăc (și nu aritác, cum, greșit, apare în Gămulescu 1974/166, preluând, mecanic, din ALRM II, s. n., 1956, forma aritac) din punctul cartografic 36 (= localitatea bănățeană Ghilad) are pluralul arităce, fiind, de fapt, clar, un s. n. Peste ani, tot redacția clujeană a DLR (s. n.), utilizând însă doar sursa: „NALR-B 2028”, va acorda, corect, statut de variantă lexicală (v., infra, 2.9.2.) și formei arítăc (atestată și în ALR II 5012/4, precum, tot în această sursă, dar în punctul de anchetă 8 , este atestată și forma lexicală oritác).

2.9.2. În DLR 2002/340, este lucrat următorul articol lexicografic re c u perat or:

„URITÁC s. n. = oritac. Cf. NALR-B 2082/54, 84, 86. - Pl.: uritace. - Și: oritắc $[\ldots]$, urétic $[\ldots]$, urétăc (pl. uretăci $[\ldots])$, urécăt (pl. urecăte [...]), urechet $[\ldots]$, aritác $[\ldots]$, arítăc $([\ldots]$ pl. și $\operatorname{arităci}[\ldots])$, arétic $[\ldots] "$.

2.9.3. În MDA 2003, III/ 847 , este lucrat următorul articol lexicografic independent:

,oritac $s$ [At: ALRM SN I, h 17/47/ V: (reg) teg/ Pl: nct/ E: srb oritak] (Ban) Lopățică folosită la curățirea plugului de pământ”,

articol ce, lacunar, rescrie articolul de sub 2.9.1.

2.9.4. În MDA 2003, IV, sunt lucrate, i n c o r e c t și 1 a c u n a r, pe baza articolului lexicografic recuperator de sub 2.9.2., următoarele patru articole lexicografice de trimitere:

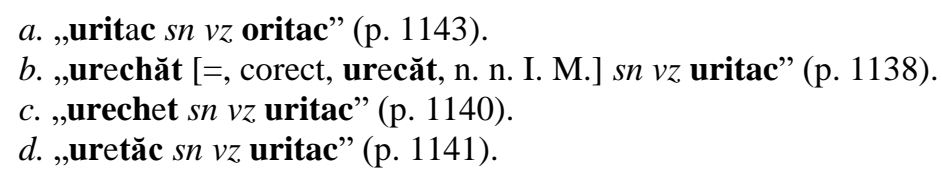

Note.

1) Redactarea celor patru articole lexicografice de trimitere, reproduse sub 2.9.4., este incorectă pentru că nu numai forma lexicală uritác trebuia trimisă la forma-titlu oritác, ci și celelalte trei forme (: urécăt, urechét și urétăc) trebuiau trimise la aceeași formă-titlu, așa cum, limpede, indică articolul lexicografic de sub 2.9.2. 
2) Redactarea numai a celor patru articole de trimitere este și lacunară pentru că n-am înțeles de ce asemenea articole lexicografice de trimitere la forma-titlu oritác nu s-au realizat, absolut obligatoriu, și pentru variantele lexicale aritác, aritắc și arétic?!

3) Rescrierea articolelor lexicografice recuperatoare numai ca articole lexicografice de trimitere este, cum am subliniat în precizare introductivă 1.4., la fel de greșită ca rescrierea acestora ca articole lexicografice in de pende n te. Toate, dar absolut toate formele lexicale (inclusiv forma lexicală intrare = lemă) prezente în articolul lexicografic de întregire trebuie să fie prezente și în cadrul articolului lexicografic ce trebuie întregit.

2.9.5. Concluzionând, vom spune că, rescriind c o r e c t (= în conformitate cu realitatea lexicografică conținută în articolul lexicografic întregitor din DLR 2002/340), redacția MDA trebuia să elaboreze, în locul articolului lexicografic r e c u p e r a t o r, 7 articole lexicografice de trimitere, pe de o parte, iar, pe de altă parte, să întregească articolul lexicografic independent de sub 2.9.3. cu variantele lexicale: oritắc, urétic, urétăc, urécăt, urechét, uritác, aritác, arítăc și arétic.

2.10. „URMÁN s. n. = orman ${ }^{1}$.

2.10.1. În DLR 1969/315-316, este lucrat următorul articol lexicografic i nde pe nde n t:

„ORMÁN ${ }^{1}$ s. n. (Ban.) Dulap; sipet, scrin. [...]. Lada miresei [...]. - Pl.: ormane. - Din scr. orman".

2.10.2. În DLR 2002/356, este lucrat următorul articol lexicografic r e c u p e r a t or:

$$
\text { „URMÁN s. n. = orman' }{ }^{1} \text { [ [...]”. }
$$

2.10.3. În MDA 2003, III/848, este lucrat următorul articol lexicografic ind e pendent:

„orman' ${ }^{1} s n$ (At: LIUBA-IANA, M. 98/ Pl: el E: srb orman] (Ban) 1 Dulap. 2 Ladă a miresei”,

articol ce, lacunar și în maniera semasiologică a MDA, rescrie articolul de sub 2.10.1.

2.10.4. În MDA 2003, IV/1145, este lucrat următorul articol lexicografic de trim it e r e:

$$
\text { „urman } s n v z \text { orman" }{ }^{1}, \text {, }
$$

articol ce rescrie, c o r e c t, articolul lexicografic recuperator de sub 2.10.2., pe de o parte, iar, pe de altă parte, g r e și t, neîntregind articolul lexicografic independent de sub 2.10.3. cu varianta lexicală urmán.

2.11. „UȘTORÓȘ s. m. = (regional) oștorâș”.

2.11.1. În DLR 1969/371, este lucrat următorul articol lexicografic independent: 
„OȘTORÂȘ s. m. (Prin nordul Transilv.) Băiat care mână boii prinși în jug (la arat); pogonici. Cf. VAIDA, CABA, SĂL. 99. - Pl.: oștorâşsi. - Şi: oștorój s. m. ALR I 896/389. - Din magh. ostoros".

2.11.2. În DLR 2002/442, este lucrat următorul articol lexicografic recuperat or:

„UȘTORÓȘ s. m. = (regional) oștorâș [...]. ALR I 896/298”.

2.11.3. În MDA 2003, III/860, este lucrat următorul articol lexicografic independent:

„oștorâș sm [At: VAIDA/ V: (reg) roj/ Pl: -i/ E: mg ostoros] (Trs) Țăran care mână boii la arat Si: pogonici",

articol ce, 1 a c u n a r și cu modificarea (nefericită) a definiției, rescrie articolul de sub 2.11.1.

2.11.4. În MDA 2003, IV/1157, este lucrat următorul articol lexicografic in $d$ e pende $n t$ :

„uștoroș sm [At: ALR I, 896/298/ Pl: ?/ E: nct] (Reg) Oştorâş”,

articol ce, din ignoranță lexicografică, rescrie articolul r e c u p e r a t o r de sub 2.11.2. ca articol lexicografic i n d e p e $n d$ e $n t$, forma lexicală regională uștoróș fiind, astfel, considerată ca reprezentând o altă unitate lexicală independentă, cu „etimologia necunoscută” (și definită sinonimic tot printr-un regionalism), când, de fapt, în realitatea lexicografică înregistrată de redacția DLR (s. n.), avem de-a face cu o altă variantă lexicală a formei-titlu oștorâș, cum, de altfel, ne anunță chiar redacția clujeană a DLR 2002/442 prin formularea titlului articolului lexicografic (întregitor): „UȘTORÓȘ s. m. = (regional) oștorâș”.

2.11.5. Concluzionând, vom spune că, rescriind c o r e c t (= în conformitate cu realitatea lexicografică conținută în articolul lexicografic întregitor din DLR 2002/442), redacția MDA trebuia să elaboreze, în locul articolului lexicografic recuperator, doar un articol lexicografic de trimitere: „uștoroș $s m v z$ oștorâș", pe de o parte, iar, pe de altă parte, să completeze articolul lexicografic de sub 2.11.3. cu varianta lexicală uștoróș.

2.12. „USTTUBÉU s. n. = (regional) ștubeu”.

2.12.1. În DLR 1978/235, este lucrat următorul articol lexicografic i ndependent:

„ȘTUBÉU s. n. 1. (Prin Munt.) Stup primitiv, făcut dintr-un trunchi de copac scorburos sau scobit. Cf. H IV 85.

2. (Munt.) Fântână cu izvorul la mică adâncime, care are ca ghizd un trunchi de copac scorburos sau scobit. [...].

3. (Regional) Groapă adâncă; p. e x t. râpă, văgăună [...].

- Pl.: ştubeie. - Și: știubéu [...], uștiubéu [...].

- Cf. ș t i u b e i'”. 
2.12.2. În DLR 2002/442, este lucrat următorul articol lexicografic recuperator:

„UȘTUBÉU s. n. = (regional) ștubeu.

1. (Prin Munt. și nord-estul Olt.) Ștubeu (2). [...]. • (Prin sudul Munt.) Cișmea. [...].

2. (Prin Munt.) Ștubeu (3). [...] Groapă mică în pământ unde stă fierarul cu picioarele când lucrează la vatra din fierărie".

2.12.3. În MDA 2003, IV/805, este lucrat articolul lexicografic i n d e pendent:

„ștubeu sn [At: H IV, 85/ V: (reg) știu , uștiu / Pl: eie/ E: ns cf știubei ${ }^{1}$ ] (Mun) 1-2 Știubei ${ }^{1}(\mathbf{3}, 7) .3$ (Reg) Groapă adâncă. 4 (Reg; pex) Râpă”,

articol ce, lacunar, rescrie articolul de sub 2.12.1.

2.12.4. În MDA 2003, IV/1157, este lucrat următorul articol lexicografic i ndependent:

„uștubeu sm [A: H IV, 82/ Pl: ?/ E: nct] 1 (Mun; Olt) Ștubeu (2). 2 (Mun) Ștubeu (3). 3 (Mun) Groapă mică în pământ unde stă fierarul cu picioarele când lucrează la vatra din fierărie",

articol ce, din ignoranţă lexicografică, rescrie articolul re c u p e r a t o r de sub 2.12.2. ca articol lexicografic i n d e p e n d e n t, forma lexicală regională uștubéu fiind, astfel, considerată ca reprezentând o altă unitate lexicală independentă, cu „etimologia necunoscută”, când, în realitatea lexicografică înregistrată de redacția DLR (s. n.), avem de-a face doar cu o altă variantă lexicală a formei-titlu ștubéu, cum, de altfel, ne anunță chiar redacția clujeană a DLR 2002/442 prin formularea titlului articolului lexicografic (întregitor): „UȘTUBÉU s. n. = (regional) ștubeu”.

2.12.5. Concluzionând, vom spune că, rescriind c o r e c t (= în conformitate cu realitatea lexicografică conținută în articolul lexicografic întregitor din DLR 2002/442), redacția MDA trebuia să elaboreze, în locul articolului lexicografic r e c u p e r a t o r, un simplu articol lexicografic de trimitere: „uștubeu $s n$ [și nu $s m$, cum, dintr-o greșeală de culegere neobservată, apare în MDA] vz ștubeu”, pe de o parte, iar, pe de altă parte, să întregească articolul lexicografic de sub 2.12.3. cu varianta lexicală uștubéu, (sub)sensurile „cișmea” și „groapă mică în pământ [...]", precum și areal sensul 1.

2.13. „UTÁLM s. n. = (învechit) otalm”.

2.13.1. În DLR 1969/372, este lucrat următorul articol lexicografic i nde pende nt:

„OTÁLM s. n. (Învechit) Apărare, ocrotire. ANON. CAR., cf. DR. IV, 156. Din magh. o(l)talom".

2.13.2. În DLR 2002/451, este lucrat următorul articol lexicografic recuper a t or:

„UTÁLM s. n. = (învechit) otalm. [...]”. 
2.13.3. În MDA 2003, III/860, este lucrat următorul articol lexicografic i nde pe nde n t:

„otalm sn (At: ANON. CAR./ Pl: ?/ E: mg o(l)talom] 1 Apărare. 2 Ocrotire”,

articol ce, 1 a c u n a r, rescrie articolul lexicografic de sub 2.13.1.

2.13.4. În MDA 2003, IV/1158, este lucrat următorul articol lexicografic de trimitere:

„utalm sn vz otalm”,

articol ce rescrie, c orect, articolul lexicografic recuperat or de sub 2.13.2., pe de o parte, iar, pe de altă parte, g r e și t, neîntregind articolul lexicografic independent de sub 2.13.3. cu varianta lexicală utálm.

2.14. „UTĂLMĂZUí vb. IV = (învechit, prin Ban. și vestul Transilv.) otălmăzui”.

2.14.1. În DLR 1969/373, este lucrat următorul articol lexicografic i n d e p e nde n t:

„OTĂLMĂZUí vb. IV T r n z. (Învechit) A apăra, a ocroti, a proteja. [...]. Prez. ind.: otălmăzuiesc. - Din magh. oltalmaz, ótalmaz".

2.14.2. În DLR 2002/451, este lucrat următorul articol lexicografic r e c u per a t o r:

„UTĂLMĂZUÍ vb. IV = (învechit, prin Ban. și vestul Transilv.) otălmăzui. [...]".

2.14.3. În MDA 2003, III/860, este lucrat următorul articol lexicografic i n d e pendent:

,otălmăzui $v t$ (At: CORESI, M. 256/12/ Pzi: iesc/ E: mg oltalmaz, ótalmaz] (Înv.) A ocroti”,

articol ce, 1 a c u n a r, rescrie articolul lexicografic de sub 2.14.1.

2.14.4. În MDA 2003, IV/1158, este lucrat următorul articol lexicografic de t r i m i t er e:

„utălmăzui $v$ vz otălmăzui”,

articol ce rescrie, corect, articolul lexicografic recuperator de sub 2.14.2., pe de o parte, iar, pe de altă parte, g r eși t, neîntregind articolul lexicografic independent de sub 2.14.3. cu varianta lexicală utălmăzuí.

2.15. „UTVÁI subst. = odor ${ }^{3}$ ”.

2.15.1. În DLR 1969/137, este lucrat următorul articol lexicografic i ndepende nt:

„ODÓR ${ }^{3}$ s. n. (Nord-vestul Transilv.) Curte. Cf. DDRF, H XVII/21, BRAN, S., VAIDA. [...] - Pl.: odoare și (rar) odoruri (ALR I 672/343 [...]). - Din magh. udvar". 
2.15.2. În DLR 2002/458, este lucrat următorul articol lexicografic r e c u perator:

„UTVÁI subst. = odor ${ }^{3}$. (Regional) Loc pe care pasc oile; imaș (Bârla Bistrița). Cf. CHEST. V 21/7".

2.15.3. În MDA 2003, III/809, este lucrat următorul articol lexicografic i ndepende $\mathrm{t}$ :

„odor ${ }^{3} s n$ [At: DDRF/ Pl: oare şi (rar) uri/ E: mg udoar] (Trs) Curte”,

articol ce, l a c u na r și cu greșeli (privind forma etimonului și menționarea primei atestări), rescrie articolul de sub 2.15.1.

2.15.4. În MDA 2003, IV/1159, este lucrat următorul articol lexicografic independent:

„utvai $s$ [At: CHEST. V 21/7/ Pl: ?/ E: nct] (Reg) Loc pe care pasc oile Si: imaş”,

articol ce, din ignoranţă lexicografică, rescrie articolul r e c u p e r a t o r de sub 2.15.2. ca articol lexicografic i n d e p e $n d$ e $n t$, forma lexicală regională utvái fiind, astfel, considerată ca reprezentând o altă unitate lexicală independentă, cu „etimologie necunoscută”, când, de fapt, în realitatea lexicografică înregistrată de redacția DLR (s. n.), avem de-a face cu o variantă lexicală a formei-titlu odór $\mathbf{r}^{3}$, cum, de altfel, ne anunță chiar redacția clujeană a DLR 2002/458 prin formularea titlului articolului lexicografic (întregitor): „UTVÁI subst. = odor ${ }^{3}$ ”.

2.15.5. Concluzionând, vom spune că, rescriind c o r e c t (= în conformitate cu realitatea lexicografică conţinută în articolul lexicografic întregitor din DLR 2002/458), redacția MDA trebuia să elaboreze, în locul articolului lexicografic r e c u p e r a t or, doar un articol lexicografic de trimitere: „utvai $s$ vz odor ${ }^{3}$, pe de o parte, iar, pe de altă parte, să completeze articolul lexicografic de sub 2.15.3. cu varianta lexicală utvái.

2.16. ,VOLÚNGĂ s. f. (Prin Olt.) = bolândă”.

2.16.1. În DLR 2005/1046, este lucrat următorul articol lexicografic recuperator:

„VOLÚNGĂ s. f. (Prin Olt.) = bolândă. Fetelor, volunjelor, [...]. - Pl.: volunge".

2.16.2. În MDA 2003, IV/1303, este lucrat următorul articol lexicografic i ndependent:

„volungă $s f$ [At: ȘEZ. XIII, 206/ Pl: -nge/ E: nct] (Olt) Cuvânt cu sens neprecizat",

articol ce, din ignoranță lexicografică, rescrie articolul r e c u p e r a t o r de mai sus (= de sub 2.16.1.) ca articol lexicografic i n d e p e n d e nt, forma lexicală regională volúngă fiind, astfel, considerată ca reprezentând o altă unitate lexicală, cu „etimologie necunoscută” și ,sensul neprecizat”, când, de fapt, în realitatea lexicografică prezentată de DLR (s. n.), avem de-a face cu o altă variantă lexicală a 
cuvântului „,bolând,-ă”, pentru care v. MDA 2001/294, cum, de altfel, ne anunță chiar redacția ieșeană a DLR 2005/1046 prin formularea titlului articolului lexicografic (întregitor): „VOLÚNGĂ s. f. (Prin Olt.) = bolândă”.

2.16.3. Concluzionând, vom spune că, rescriind c o r e c t (= în conformitate cu realitatea lexicografică conținută în articolul lexicografic întregitor din DLR 2005/1046), redacția MDA trebuia să elaboreze, în locul articolului lexicografic r e c u p e r a t o r, doar un articol lexicografic de trimitere: „volungă $s f$ vz bolând, $\sim \breve{a}$ ", pe de o parte, iar, pe de altă parte, să completeze articolul lexicografic i n d e p e n d e n t ,,bolând, ă”, din MDA 2001/294, cu varianta lexicală volúngă.

2.17. „VREASCÓTĂ s. f. = rascotă”.

2.17.1. În DLR 1975/42, este lucrat următorul articol lexicografic independe n t:

„RÁSCOTĂ s. f. (Regional; de obicei la pl.) Creangă uscată, surcea; vreasc. Cf. BARONZI, L. 118. [...]. - Pl.: rascote. - Etimologia necunoscută. Cf. r a s c (o variantă a lui vreasc)".

2.17.2. În DLR 2005/1233, este lucrat următorul articol lexicografic recuperat or:

„VREASCÓTĂ s. f. $=$ rascotă. [...]. $-\mathrm{Pl}$.: vreascote”.

2.17.3. În MDA 2003, IV/127, este lucrat următorul articol lexicografic independent:

„,rascotă $s f$ [At: BARONZI, L. 118/ Pl: te/ E: ns cf rasc] (Reg; de obicei lpl) Vreasc",

articol ce, 1 a c u n a r, rescrie articolul lexicografic de sub 2.17.1.

2.17.4. În MDA 2003, IV/1314, este lucrat următorul articol lexicografic de trimitere:

„vreascotă $s f \mathrm{vz}$ rascotă”,

articol ce rescrie, c orect, articolul lexicografic recuperator de sub 2.17.2., pe de o parte, iar, pe de altă parte, g r e ș i t, neîntregind articolul lexicografic de sub 2.17.3. cu varianta lexicală vreascótă.

\subsection{ETC. ETC. ETC.}

\section{Precizări f i n a l e:}

3.1. În prezenta în s e m n a r e 1 e x i c a lă ne-am oprit doar la 17 dintre numeroasele (v., infra, 3.4.) articole lexicografice întregitoare $=$ recuperatoare existente în DLR (s. n.), redactând 17 note lexicografice, suficiente, considerăm, pentru a vedea, practic, cum articolele la care ne-am oprit au fost rescrise, în totală necunoștință de cauză, în MDA. 
3.2. Dintre cele 17 articole lexicografice recuperatoare din DLR rescrise de redacția MDA, 12 au fost redactate ca articole lexicografice independente, sporind (astfel) cu 12 unități lexicale numărul cuvintelor-titlu, pe de o parte, iar, pe de altă parte, 5 (= 2.9., 2.10., 2.13., 2.14. și 2.17.) au fost redactate doar ca articole lexicografice de trimitere. Ambele tipuri de reredactare sunt, mai repetăm o dată, la fel de greșite.

3.3. Considerând cele $17(=\mathbf{2 . 1}-\mathbf{- 2 . 1 7}$.) note lexicografice pe care le-am redactat ca fiind suficiente întru concretizarea precizărilor introductive, am suspendat redactarea și a altora, exceptând, bineînțeles, nota 2.18., intitulată: Etc. etc. etc.

3.4. Vom prezenta, însă, în cadrul acestui paragraf, și existența celorlalte articole lexicografice recuperatoare depistate de noi în DLR (s. n.), exceptându-le, desigur, pe cele (doar câteva) valorificate de noi ca note lexicografice redactate și publicate anterior prezentei însemnări. Este vorba despre următoarele articole lexicografice:

3.4.1. negăí vb. = migăli (DLR 1971/230); - negăiálă ${ }^{2}$ s. f. $=$ migăleală $(D L R$ 1971/230); - negăiós, -oásă adj. = migălos (DLR 1971/230); - țarțoáne subst. pl. = sărsam (DLR 1994/21); - târcalíci subst. pl. = tărcăliṣ (DLR 1994/183); udiní vb. = odihni (DLR 2002/20); - uiúdum s. n. sg. = oidium (DLR 2002/44; umbraníc s. m. = dumbravnic (DLR 2002/108); - umbreájă s. f. = mreajă (DLR 2002/116); - urațiúne s. f. = orație (DLR 2002/281); - uruzán s. n. = orozan (DLR 2002/395); - urzésc, - eáscă adj. = orzesc (DLR 2002/397); - ușlóg s. n. = șlag1 (III 1) (DLR 2002/434); - uștiuléte s. m. = știulete (DLR 2002/442) și úță4 ${ }^{4}$. f. = huță (DLR 2002/458).

Note:

1. În MDA 2003, III/715, articolele lexicografice negăí, negăială² și negăiós, -oásă sunt rescrise, ca articole lexicografice independente, astfel:

a. „negăi vi [At: I. CR. VI, 314/ Pzi: nct/ E: nct] (Mol) 1 [...]. 2 A lucra cu multă minutiozitate Si: a migăli’"

b. ,negăială² $s f$ [At: POLIZU/ PI: ieli/ E: negăi + -eală] (Mol) Migăleală”.

c. „negăios, oasă $a$ [At: RUSSO. S. 78/ Pl: oși, oase/ E: negăi + -os] (Mol) Migălos".

Precizând că intranzitivul negăí nu este sinonim cu verbul migălí (v. MDA 2003, III/563), ci această formă lexicală verbală, cum corect se menționează în DLR 1971/230, nu este, precum forma migăí, decât o altă variantă lexicală a acestuia, variantă care, provenind din Moldova, cred că trebuie literarizată megăí. Tot variante lexicale ale cuvintelor titlu migăleálă și migălós, -oásă (v. MDA 2003, III/563) trebuie considerate, cum corect a menționat redacția bucureșteană a DLR 1971/230, și formele lexicale negăiálă ${ }^{2}$ și, respectiv, negăiós, -oásă, care, fiind și ele din Moldova, trebuie literarizate megăiálă, respectiv megăiós, -oásă.

2. În DLR 2002/116, redacția clujeană a DLR (s. n.) a lucrat următorul articol lexicografic recuperator:

„UMBREÁJĂ s. f. = mreajă. (Prin sud-estul Transilv.) Element decorativ la costumul popular românesc, cusut pe mânecile și pieptul cămășii (PĂCALĂ, M. R. 
519) sau pe mânecile iei de la altiță în jos până la pumnași, r â u (3) (com. din BRANZĂRNEȘTI); cusătură decorativă, mai lată de un deget, cu care se încheie marginile cămășii țăănești, c h e iță (BREBENEL, GR. P.). Mânecile și pieptul [cămășii] se impodobesc cu ornamente filigrane de forme foarte varii.., spărtura, umbrejile, beata. PĂCALĂ, M. R. 518",

articol rescris, ca articol lexicografic independent, în MDA 2003, IV/1112:

„umbreajă sf [At: PĂCALĂ, M. R. 519 [sic! - n. n. I. M.]/ Pl: ?/ E: nct] 1 (Reg) Plasă de pescuit Si mreajă [...]".

Înțelegem că, din neștiință, redacția MDA 2003, IV/1112, în loc să elaboreze (corect) un simplu articol lexicografic de trimitere (: umbreájă vz mreajă), cum ne îndeamnă redacția clujeană (chiar) prin titlul articolului lexicografic întregitor reprodus mai sus, pe de o parte, iar, pe de altă parte, toată informația lingvistică recuperată să o trimită pentru a fi fructificată în rescrierea articolului lexicografic independent intitulat mreájă (vezi-l în MDA 2003, III/639). Nu înțelegem, însă, cum primul sens (= „1. Plasă de pescuit simplă, ușoară, împletită cu ață foarte subțire [...]”) al cuvântului-titlu mreajă a ajuns, tot pe primul loc, în rescrierea variantei lexicale umbreájă ca un alt cuvânt-titlu.

3. În legătură cu articolul lexicografic recuperator: „ușlóg s. n. = șlag " din DLR 2002/434, trebuie precizat că forma lexicală ușlóc nu este o variantă lexicală a cuvântuluititlu ușlóg (v. MDA 2003, IV/1156), ci, evident, ambele forme lexicale, ușlóg şi ușlóc, sunt variante lexicale ale cuvântului-titlu șlag ${ }^{1}$ (pentru care, v. MDA 2003, IV/767).

4. În legătură cu articolul lexicografic recuperator: „uştiuléte s. m. = știulete” din DLR 2002/442, trebuie precizat că forma lexicală uştuléte nu este o variantă lexicală a cuvântului-titlu uștiuléte (v. MDA 2003, IV/1157), ci, desigur, ambele forme lexicale, uștiuléte și uștuléte, sunt variante lexicale ale cuvântului-titlu știulete (pentru care, v. MDA 2003, IV/802).

3.4.2. toptiloácă $s$. f. = pitpalacă (DLR 1983/422); - țăcălúșă $\mathrm{s}$. f. = săcăluṣ (DLR 1994/23); - țăgăráş $\mathrm{s}$. m. = sechiraș (DLR 1994/24); - țắnic $\mathrm{s} . \mathrm{n} .=$ senic (DLR 1994/28); - țărsám s. n. = sărsam (DLR 1994/42); - țeflíu s. m. = secfiu ${ }^{1}$ (DLR 1994/51); - țepelígă² s. f. = săpăligă (DLR 1994/59); - țidil subst. = sedilă ${ }^{1}$ (DLR 1994/81); - țiflingár s. m. = cioflingar (DLR 1994/83); - țițigáie s. f. = pițigaie $^{1}$ (DLR 1994/167); - țițigoáică s. f. = pițigoaică (DLR 1994/167); - țițigoi s. m. = pițigoi (DLR 1994/167); - țițiguș s. m. = pițiguș (DLR 1994/167); țîștóc ${ }^{2}$ s. n. = tirștoc (DLR 1994/195); - țîțîág s. n. = sîsîiag (DLR 1994/200); țócru s. n. = soclu (DLR 1994/206); - țupancă s. f. = topancă (DLR 1994/226); țvánțig s. m. = sfanț (DLR 1994/240); - ucít adv. = ocit (DLR 2002/14); - udátă adv. = odată ${ }^{2}$ (DLR 2002/18); - uiéne s. f. pl. = oiene (DLR 2002/26); - ulói ${ }^{1}$ s. n. = oloi ${ }^{1}$ (DLR 2002/108); - umétiță s. f. = ometiță (DLR 2002/126); - unctuós, -oásă = adj. onctuos (DLR 2002/162); - undulătór, -oáre adj. = ondulator (DLR 2002/183); - undulățiúne s. f. = ondulație (DLR 2002/183); - uprelestít, -ă adj. = prilestit (1) (DLR 2002/276); - urbíş adv. = orbiș (DLR 2002/273); - urjóg s. n. = ojog (1) (DLR 2002/342); - urzíu, -íe adj. = orziu (DLR 2002/406); - uspăciói $\mathrm{s}$. m. = ospecioi (DLR 2002/421); - uspătá vb. = ospăta (DLR 2002/422); - uspătáre s. f. = ospătare (DLR 2002/422); - uspătát, -ă adj. = ospătat ${ }^{2}$ (DLR 2002/422); - 
uspătioi s. m. = ospătoi (2) (DLR 2002/422); - uspeciór s. m. = ospecior (DLR 2002/422); - uspețeán s. m. = ospețean (DLR 2002/422); - uspețíe s. f. = ospeție (3) (DLR 2002/422); - uspețói s. m. = ospătoi (2) (DLR 2002/422); - ustănít, -ă adj. = ostenit ${ }^{1}$ (DLR 2002/423); - usteí vb. = ostoi ${ }^{2}$ (DLR 2002/423); - ustenitór s. m. = ostenitor (2) (DLR 2002/423); - ustiá vb. = ostoi² (DLR 2002/423); - ustuí vb. = ostoi ${ }^{2}$ (DLR 2002/423) și ustuít, -ă adj. = ostoit (2) (DLR 2002/423).

Note:

1. Articolul recuperator țițigói din DLR 1994/167 are, pe lângă forma-titlu, și alte două forme lexicale înregistrate la sfârșitul articolului, prin formula lexicografică: „Şi: țițigui, țițingău", forme pentru care redacția MDA elaborează, pe lângă articolul lexicografic de trimitere: „tițigoi $s m v z$ pițigoi”, și următoarele două articole:

a. „țitigui $s m v z$ pițigoi”.

b. „țitingău $s m v z$ țițigoi”.

Corect era, desigur, ca pentru toate cele trei forme lexicale prezente în articolul întregitor să se elaboreze câte un articol lexicografic de trimitere la pițigoi, pe de o parte, iar, pe de altă parte, toate cele 3 forme lexicale să fie incluse (împreună cu celelalte informații lingvistice întregitoare prezente în articolul recuperator) și în rescrierea articolului lexicografic independent pițigói (v. MDA 2003, III/1074).

2. În cadrul articolului lexicografic recuperator ,țiflingar = cioflingar”, DLR 1994/83 înregistrează și forma lexicală țiflindér pentru care MDA 2003, III/1067 redactează următorul articol lexicografic de trimitere: „, tiflinder $s m v z$ țiflingar”, urmat (imediat), prin rescrierea articolului recuperator numai ca articol de trimitere, de articolul: ,tiflingar $s m v z$ cioflingar".

3. La articolul întregitor ,ț̂ttîiág = sîsîág” din DLR 1994/200 avem și forma lexicală țuțuiág, formă pentru care MDA 2003, IV/1095 redactează următorul articol de trimitere: ,țuțuiag $s n v z$ țâțâiag". Pentru forma-titlu a articolului recuperator înregistrează articolul: ,,țațâiag $s n v z$ sâsâiag” (MDA 2003, III/1056), dar, trebuie precizat, un articol lexicografic independent sâsâiag nu există în MDA, ci numai articolul sâsâiac (v. MDA 2003, IV/340).

3.5. Sub 3.4.1. am enumerat 15 articole lexicografice recuperatoare prezente în DLR, s. n., articole ce au fost rescrise, g r e ș i t, ca articole lexicografice independente de către redacția MDA.

3.6. Sub 3.4.2. am înşirat 45 de articole lexicografice recuperatoare prezente în DLR, s. n., articole ce au fost rescrise, 1 a f e $1 \mathrm{~d}$ e $\mathrm{g} \mathrm{r}$ e ș i t, numai ca articole lexicografice de trimitere de către redacția MDA.

3.7. În total, au rămas, așadar, 60 de articole lexicografice recuperatoare pentru care, întristându-mă prea tare, nu am mai elaborat, în maniera redacțională adoptată sub 2.1. - 2.17., tot atâtea alte note lexicografice, fapt (principalul motiv) pentru care am suspendat și redactarea lor.

3.8. Încheind prezenta însemnare lexicografică, ne întrebăm exclamând: Cum, Doamne, a fost posibilă (şi) o asemenea ispravă lexicografică academică?! 


\section{ABREVIERI BIBLIOGRAFICE. SIGLE}

ALR II, s. n. 1956 = Atlasul lingvistic român. Partea a II-a, serie nouă, de Emil Petrovici, redactor principal: Ioan Pătruț, vol. I, București, Editura Academiei.

ALRM II, s. n., 1956 = Micul Atlas lingvistic român. Partea a II-a, serie nouă, de Emil Petrovici, redactor principal: Ioan Pătruț, vol. I, București, Editura Academiei.

Chest ALR II 1988 = Chestionarul Atlasului lingvistic român II, elaborat [...] de Emil Petrovici și editat [...] de Doina Grecu, I. Mării, Rodica Orza, S. Vlad; coordonator: I. Mării, Cluj-Napoca, Universitatea din Cluj-Napoca, Institutul de lingvistică și Istorie Literară.

DA 1934 = Academia Română, Dicționarul limbii române. Tomul II, partea I: F-I, București.

DLR 1965-1968; 1969; 1971; 1975; 1978; 1982; 1983; 1994; 2002; 2005 = Academia Română, Dicționarul limbii române (DLR), serie nouă, tom. VI, litera M, 1965-1968; tom. VII, partea a 2-a, litera O, 1969; tom. VII, partea 1, litera N, 1971; tom. IX, litera R, 1975; tom. XI, partea 1, litera Ș (1978); tom. XI, partea a 2-a, litera T: t - tocăliță, 1982; tom. XI, partea a 3-a: tocăna twist, 1983; tom. XII, partea 1, litera T, 1994; tom. XII, partea a 2-a, litera U, 2002; tom. XIII, partea a 3-a, litera V: vîclă - vuzum, și literele W, X, Y, 2005, București, Editura Academiei Române.

Gămulescu 1974 = Dorin Gămulescu, Elemente(le) de origine sârbocroată ale vocabularului dacoromân, București, Editura Academiei.

MDA 2001; 2002; 2003, III; 2003, IV = Academia Română, Institutul de Lingvistică „Iorgu Iordan Al. Rosetti”, vol. I, A-C 2001; vol. II, D-H 2002; vol. III, I-Pr., 2003; vol. IV, Pr.-Z, 2003, București, Editura Univers Enciclopedic.

Suciu 2010 = Emil Suciu, Influența turcă asupra limbii române, II, Dicționarul cuvintelor românești de origine turcă, București, Editura Academiei Române.

\section{SOME REMARKS ON A SPECIFIC TYPE OF LEXICOGRAPHIC ENTRY IN DLR AND MDA (Abstract)}

In this article I begin by describing the specific type of lexicographic entry which is used in order to give information that would have properly belonged to a previous entry, but which was not available at the time when that previous entry was written. I then go on to give some examples of such entries in DLR and point to how these entries were misinterpreted by lexicographers working on MDA. In the second half of this article I indicate the correct lexicographic treatment of some of these entries and signal other headwords from DLR whose counterpart entries in MDA also need correcting.

Cuvinte-cheie: lexicografie, lexicologie, etimologie, ucióci; ulogít, -ă; umizí; umizíre; undér uninea; únterșlag; úrdie; uritác; urmán; uștoróş; uștubéu; utálm; utălmăzuí; utvái; volúngă vreascótă.

Keywords: lexicography, lexicology, etymology, ucióci; ulogít, -ăa umizí; umizíre; undér; uninea; únterșlag; úrdie; uritác; urmán; uștoróș; uștubéu; utálm; utălmăzuí; utvái; volúngă; vreascótă.

Institutul de Lingvistică și Istorie Literară „Sextil Pusccariu” al Academiei Române

Cluj-Napoca, str. E. Racoviţă, 21 